\title{
Contextual Route Recommendation System in Heterogeneous Traffic Flow
}

\author{
Surya Michrandi Nasution ${ }^{1}$ (D), Emir Husni ${ }^{1, *}$, Kuspriyanto Kuspriyanto ${ }^{1}$, Rahadian Yusuf ${ }^{1}$ \\ and Bernardo Nugroho Yahya ${ }^{2}$
}

1 School of Electrical Engineering, Institut Teknologi Bandung, Jl. Ganesa 10, Bandung 40132, Indonesia; michrandi@telkomuniversity.ac.id (S.M.N.); kuspriyanto@yahoo.com (K.K.); Yrahadian@itb.ac.id (R.Y.)

2 Department of Industrial \& Management Engineering, Hankuk University of Foreign Studies Global Campus, Oedae-ro 81, Mohyeon-eup, Cheoin-gu, Yongin 17035, Gyeonggi, Korea; bernardo@hufs.ac.kr

* Correspondence: ehusni@lskk.ee.itb.ac.id

check for updates

Citation: Nasution, S.M.; Husni, E.; Kuspriyanto, K.; Yusuf, R.;

Yahya, B.N. Contextual Route

Recommendation System in

Heterogeneous Traffic Flow.

Sustainability 2021, 13, 13191.

https://doi.org/10.3390/su132313191

Academic Editors: Jacek Oskarbski,

Kyandoghere Kyamakya and

Miroslava Mikušová

Received: 27 October 2021

Accepted: 26 November 2021

Published: 29 November 2021

Publisher's Note: MDPI stays neutral with regard to jurisdictional claims in published maps and institutional affiliations.

Copyright: (c) 2021 by the authors. Licensee MDPI, Basel, Switzerland. This article is an open access article distributed under the terms and conditions of the Creative Commons Attribution (CC BY) license (https:// creativecommons.org/licenses/by/ $4.0 /)$.

\begin{abstract}
The traffic composition in developing countries comprises of variety of vehicles which include cars, buses, trucks, and motorcycles. Motorcycles dominate the road with $77.5 \%$ compared to other types. Meanwhile, route recommendation such as navigation and Advanced Driver Assistance Systems (ADAS) is limited to particular vehicles only. In this research, we propose a framework for a contextual route recommendation system that is compatible with traffic conditions and vehicle type, along with other relevant attributes (traffic prediction, weather, temperature, humidity, heterogeneity, current speed, and road length). The framework consists of two phases. First, it predicts the traffic conditions by using Knowledge-Growing Bayes Classifier on which the dataset is obtained from crawling the public CCTV feeds and TomTom digital map application for each observed road. The performances of the traffic prediction are around $60.78-73.69 \%, 63.64-77.39 \%$, and $60.78-73.69 \%$, for accuracy, precision, and recall respectively. Second, to accommodate the route recommendation, we simulate and utilize a new measure, called road capacity value, along with the Dijkstra algorithm. By adopting the compatibility, the simulation results could show alternative paths with the lowest RCV (road capacity value).
\end{abstract}

Keywords: route recommendation; heterogeneous traffic flow; traffic prediction; Knowledge Growing System; shortest path; machine learning

\section{Introduction}

Route planning and recommendation systems have attracted much attention in recent years [1]. Applications such as navigation systems and Advanced Driving Assistance Systems (ADAS) are becoming increasingly popular to query a trip and re used on a massive scale in cities [2]. The issues on route recommendation are not only about the way to recommend the route but also the diversity of the vehicles or users who use it. Countries, such as Indonesia, with diverse types of vehicles confront incompatibility with the applications. For example, motorcycle dominates $77.5 \%$ among other types of vehicles (passenger car, bus, and truck) [3]. This causes heterogeneous traffic and affect the traffic condition in several aspects; such as comfortability in driving [4] or the congestion [5].

Various applications have concerned about the road conditions with less consideration on the vehicle size. For example, due to the rush hours' traffic conditions, a car driver may experience to get an alternative route which is only for motorcycle driver. Previous works dealt with several attributes to define the convenience and safety of driving beside the compatibility; such as traffic condition [6-8], weather [9-12], temperature [13-15], humidity [16], travel speed [17-19], road infrastructure [20], heterogeneity [21,22], etc. None of the previous works include the vehicle size as the attribute to improve the convenience and driving safety. Meanwhile, the challenges to determine the route recommendation depends not only the aforementioned attributes but also on the current road observation. It 
is important to measure the value of road capacity to determine the proper road segments for the route recommendation.

This paper proposes a framework to build a route recommendation system by utilizing the road capacity considering traffic conditions and vehicle size. The framework starts with processing the data such as traffic condition, environments (e.g., weather, temperature, humidity), public CCTV, and digital maps. The processed data will go through the machine learning pipeline to predict the traffic conditions and road capacity value for each observed road segment. In this study, we utilize Knowledge Growing Bayes since it has been proven as a robust classifier to learn the data with a growable training data over time [23]. The driver's preference, that is the vehicle type, affect the route recommendation that is based on the minimum sum of the road capacity value on each road segment. At the end, the shortest path distance between source and destination is shown as the route recommendation.

This paper is organized as follows. Section 2 will discuss the literature review that related with the research. The proposed systems will be discussed in Section 3, followed by the simulation result and discussion in Section 4 . Finally, Section 5 will provide the conclusion of this research.

\section{Literature Review}

This section addresses several research works on route recommendations: traffic condition prediction and route recommendation. Traffic condition prediction aims to discuss the proper method to result a better prediction analysis. Route recommendation aims to explore the existing work on how to provide the best route for users. The two domains would be the parts of our framework to result contextual route recommendations in heterogeneous traffic flow.

\subsection{Prediction of Traffic Condition}

There are numerous common methods to predicts traffic condition, namely Neural Networks [24-26], Deep Neural Networks [27], and Deep Learning [28]. It works based on network which created from training data and tries to predict the next situation using the networks. Kumar et al., implemented a combination of Multi-Layer Perceptron on Neural Network configuration to predict traffic conditions [24]. Based on their results, Neural Network has consistent performance for several time intervals for traffic prediction.

Hu et al., also implemented Neural Network with Backpropagation to predict shortterm traffic [25]. They claimed Neural Network with Backpropagation is an effective method to use as short-term traffic prediction. Meanwhile, Nasution et al., tried to predict traffic conditions based on a voting system from several Neural Networks [26]. Their system delivers a better performance than conventional methods of Neural Network.

The improvement of Neural Networks also aids the prediction of the condition of traffic. Yi et al. claimed Deep Neural Network could estimate traffic congestion [27]. By using three hidden layers (40,50, and 40 neurons), the tanh activation function, and AdaGrad optimization algorithm, the system achieved $99 \%$ accuracy in predicting congestion. On the other hand, Lv et al., stated that Deep Learning can understand the traffic feature without prior knowledge. They applied Stack Autoencoders as their main method, and compared it with Backpropagation Neural Network, Random Walk, Support Vector Machine, and Radial Basis Function. It happened that their proposed method has the smallest error rate among other methods.

The prediction of a condition could be implemented in the short-term and long-term. The Autoregressive Integrated Moving Average (ARIMA) model has a capability to predicts a future condition using time series data, such traffic flow [29] or passenger flow [30]. Chen et al. predicts passenger flow in subway stations using ARIMA model and its variances (SGARCH, EGARCH, GJRGARCH, NAGARCH). Based on their results on a subway station, basic ARIMA model has the highest Mean Average Percentage Error (27.971\%). 
Meanwhile, ARIMA NAGARCH has the lowest error $(\mathrm{MAPE}=9.056 \%)$ among all the compared ARIMA models.

The other common methods for predicting the traffic condition are Decision Trees [31] and Bayesian [11,32,33]. A Decision Tree creates a classification system using Information Gain and Entropy of the data. Sujatha et al., detected traffic congestion by using this method and comparing it with the Neural Network method [31]. Even though the performance of Decision Tree is not as good as Neural Network, it can predict faster. Meanwhile, Bayesian methods predicts the situation based on the probability of the conditions [11]. Khan et al., forecasts traffic situation at junctions using Bayesian Model [32]. The traffic condition is determined based on the principles of conditional probability distributions. The accuracy rate of their system reaches $73 \%$ when predicting the 5-level traffic states. Anitha et al., uses Naïve Bayes to predict the traffic based on multi-source data [33]. According to their result, this method is not only easy to build and useful in handling a very large dataset, but it also outperforms the other highly sophisticated classification methods. In general, Decision Tree and Bayesian runs efficiently since these methods need not process the training data into another form.

Despite of the greatness of these methods, they seem incapable of handling the real-world situations which have dynamic conditions. It may appear with changes and instability of traffic conditions which are difficult to address with previous methods. In particular, there are lots of attributes that could change the traffic conditions.

The Knowledge Growing System is one of the important concepts used to deal with the mentioned changes in order to enhance the model's prediction capabilities $[34,35]$. The use of growing the data concept in conventional machine learning methods is likely to boost its performances due to the data's periodic growth over time. Figure 1 shows that data training in $t-1$ time predict the current $(\mathrm{t})$ traffic condition based its testing data. The result of this pipeline is not only to determine the traffic condition at time ( $t$ ), but also to grow the dataset using the current testing data and the prediction result.

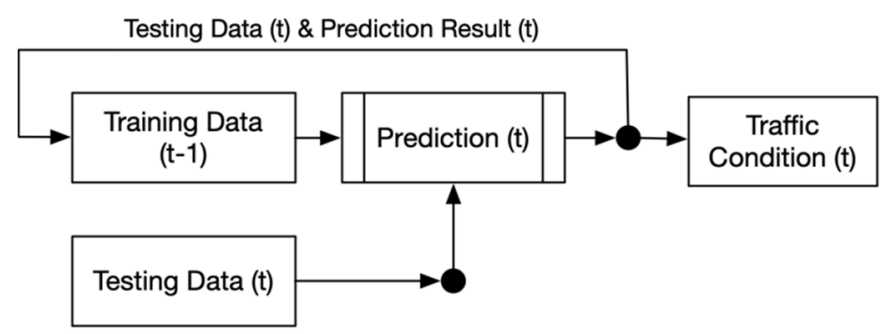

Figure 1. Scheme of Knowledge Growing Prediction Methods.

The basic concept of Knowledge Growing System tries to imitate the human's inferencing capability using their senses. In its implementation, the human's senses are replaced using sensors and its information is combined using information fusion methods in order to define a condition (or knowledge) [34]. In the Knowledge Growing System, every new condition will be stored in a knowledge database [35]. Later, whenever there is similar information that is collected, the system will easily understand the condition based on its knowledge database.

Husni et al., compared several methods for predicting the traffic condition by using the Knowledge Growing concept, and compared their performances over time [23]. Based on their results, Knowledge Growing Bayes Classifier had the highest performance gain among other methods (Knowledge Growing Deep Neural Network and Knowledge Growing Decision Tree). Knowledge Growing Bayes Classifier is also the fastest method compared to others, since it only calculates the probability of each traffic condition.

Although their method shows great results when using a dataset that grows over time, it predicts each road segment using whole map datatest and it makes the prediction not specific to selected road. Based on this situation, there will be a probability that the system will predict the traffic condition using other roads' data. The attributes that are used in 
their paper are days, time, origin, destination, road width, weather, weather location, and traffic condition.

In this paper, we applied Husni et al. Knowledge Growing concept to predict the traffic condition using each observed road segment dataset. All prediction results illustrate each road segment condition specifically. We also simplified the attributes into "Days", "Rush Hour", "Weather", "Temperature", "Traffic Condition". The attributes "Origin" and "Destination" exclude from dataset since it already specified for its road segments. The attribute of time is adjusted into rush hour status which could be used to define the traffic better. The static attribute "Road Width" also excludes from the prediction system, it also cannot describe the road situation clearly. Meanwhile the weather aspect is expanded to its condition and temperature.

\subsection{Route Recommendation}

Route recommendation aims to provide the best route for users. In order to define the recommended route, it could be calculated by using the route choice model approach. Route choice model tries to find the best path for drivers from an origin to a destination [36,37] among several alternative routes [38]. One of the most common methods in route choice model is shortest path algorithm [36,39]. It tries to determine the shortest or fastest route in a graph of road network.

Route Recommendation starts with the conversion from the road networks into directed graph which has nodes, edges, and weights. Intersections and road segments in road network will be nodes and edges in a graph. Meanwhile, the traffic conditions [40], travel distance [41], travel time [42], pricing (ridesharing) [43,44], etc. could be described as the weight of the graph. Shortest path algorithm will find the recommended route based on the weight compilation from all observed road segments by finding the minimum sum of weights from the origin to a particular destination. The compilation of weight is based on several attributes that effects situation of the road.

\section{Attributes of Road Situation}

Generally, the use of a driving assistant system to find the best route minimizes the travel time $[42,45,46]$. On the other hand, to support the convenience and safety of driving, the other attributes in driving should be considered. There are several attributes that should be used in defining the route, such as easy-driving, popular or familiar routes [47], road infrastructure (road length and width) [20], emission (eco-driving) [40,48]. Moreover, for several types of vehicle, weather is also considered as an important attribute to decide the travel route [9-16].

He et al. [49] collaborate the time and road length to find the route for taxis based on the driver's experience and preferences. By using collective intelligence, they tried to calculate top $k$-routes for the taxi drivers. Meanwhile, Kazhaev et al. [50], tried to determine the best route by reducing the conflict situation at public transportation stop-point. The conflict situation refers to competition among drivers who feel prioritized. This situation increases the throughput capacity at the stop-point, and it will inflict a congestion. The result of this research shows that the reduction in conflict situation also will minimize total delay while travelling.

Driver's preference is also something that must be considered. Based on Shenpei and Xinping [47] who consider the driver's preferences (using familiar routes) with traffic light, it could calibrate the delay time and create a strategy to passing through the signalized intersection (based on driver behavior).

The implementation of multi-attributes combination is done by Paiva et al. [51], by creating driving assistance that collects weather information, driving behavior, road situation, or condition inside the vehicle. Weather is considered as the most important attribute in the road, especially in bad weather (ice sheet).

Information of traffic congestion is also needed in order to find the best travel route. Namoun et al. used a traffic congestion for the prediction of traffic condition [40]. The infor- 
mation source that used is comes from road-side sensors and floating car. The traffic condition is used to find the best type of vehicle which has waiting time while traveling. Others existing system also tried to combine several attributes to define the routes [41,52-54].

Table 1 shows the comparison of attributes between existing and proposed framework. In this paper, the collaboration of multi-attributes is conducted which will be used as determination of the best route based on driver's preference. The attributes that are used for finding the best route are the prediction of traffic condition, weather condition, temperature, humidity, heterogeneity, current travel speed, road length and width.

Table 1. Attributes Comparison between Proposed and Existing Framework.

\begin{tabular}{|c|c|c|c|c|c|c|c|c|c|c|}
\hline & \multirow[b]{2}{*}{$\begin{array}{l}\text { Data } \\
\text { Source }\end{array}$} & \multicolumn{8}{|c|}{ Attributes } & \multirow[b]{2}{*}{$\begin{array}{c}\text { User } \\
\text { Preferences }\end{array}$} \\
\hline & & $\begin{array}{c}\text { Traffic } \\
\text { Condition }\end{array}$ & Weather & Temperature & Humidity & $\begin{array}{c}\text { Road } \\
\text { Infrastructure }\end{array}$ & $\begin{array}{l}\text { Travel } \\
\text { Time }\end{array}$ & Heterogeneity & Compatibility & \\
\hline [20] & $\begin{array}{l}\text { Electric } \\
\text { Vehicle }\end{array}$ & $\times$ & $\times$ & $\times$ & $\times$ & $\checkmark$ & $\checkmark$ & $\times$ & $x$ & $\times$ \\
\hline [45] & $\begin{array}{l}\text { Mobil } \\
\text { Robots }\end{array}$ & $\times$ & $x$ & $\times$ & $\times$ & $x$ & $\checkmark$ & $\times$ & $\times$ & $\times$ \\
\hline$[46]$ & PetriNets & $\times$ & $\times$ & $\times$ & $x$ & $x$ & $\checkmark$ & $x$ & $\times$ & $\times$ \\
\hline [42] & GPS & $x$ & $x$ & $x$ & $x$ & $x$ & $\checkmark$ & $x$ & $x$ & $x$ \\
\hline [47] & - & $\times$ & $x$ & $x$ & $x$ & $x$ & $\checkmark$ & $x$ & $x$ & $\checkmark$ \\
\hline [48] & Real Data & $\times$ & $\times$ & $\times$ & $\times$ & $\times$ & $\times$ & $\checkmark$ & $\times$ & $\times$ \\
\hline [40] & $\begin{array}{c}\text { Live Traffic } \\
\text { Data }\end{array}$ & $\checkmark$ & $x$ & $\times$ & $\times$ & $\checkmark$ & $\checkmark$ & $\times$ & $\times$ & $\times$ \\
\hline [49] & $\begin{array}{l}\text { Vehicle's } \\
\text { Trajectories }\end{array}$ & $\times$ & $\times$ & $\times$ & $\times$ & $\checkmark$ & $\checkmark$ & $\times$ & $\times$ & $\checkmark$ \\
\hline [50] & - & $\times$ & $\times$ & $\times$ & $\times$ & $x$ & $\checkmark$ & $\times$ & $\times$ & $\times$ \\
\hline [51] & $\begin{array}{c}\text { Multi } \\
\text { Sensors }\end{array}$ & $\times$ & $\checkmark$ & $\checkmark$ & $\checkmark$ & $x$ & $\times$ & $\times$ & $\checkmark$ & $\checkmark$ \\
\hline [41] & GPS Log & $\times$ & $x$ & $x$ & $x$ & $\checkmark$ & $x$ & $\times$ & $x$ & $x$ \\
\hline [52] & - & $x$ & $x$ & $x$ & $x$ & $\checkmark$ & $\checkmark$ & $x$ & $x$ & $\checkmark$ \\
\hline [53] & $\begin{array}{l}\text { Smartphone } \\
\text { \& IoT }\end{array}$ & $\times$ & $\times$ & $\times$ & $\times$ & $x$ & $\checkmark$ & $\times$ & $\times$ & $\checkmark$ \\
\hline [54] & $\begin{array}{l}\text { Real } \\
\text { Weather } \\
\text { Data }\end{array}$ & $\times$ & $\checkmark$ & $\checkmark$ & $\times$ & $\times$ & $\checkmark$ & $\times$ & $\checkmark$ & $\times$ \\
\hline $\begin{array}{l}\text { Proposed } \\
\text { Framework }\end{array}$ & $\begin{array}{l}\text { CCTV \& } \\
\text { TomTom }\end{array}$ & $\checkmark$ & $\checkmark$ & $\checkmark$ & $\checkmark$ & $\checkmark$ & $\checkmark$ & $\checkmark$ & $\checkmark$ & $\checkmark$ \\
\hline
\end{tabular}

\section{Proposed Systems}

This section discusses the proposed framework for recommending the best route based on the RCV, which is shown in Figure 2. RCV calculation is generated based on the collaboration of several attributes (prediction of traffic condition, weather information, road infrastructures, heterogeneity, and compatibility) that collected before the measurement. The proposed framework comprises of three parts; (1) Predicting the traffic condition; (2) The calculation of RCV; (3) Generating the route recommendation that compatible with the size of vehicles.

Before the system delivers the recommended route to the drivers, the traffic condition on every observed road segment will be predicted. There will be several datasets, based on the number of observed road segments. Each dataset contains some attributes such as "Days of Week", "Rush Hour", "Weather", "Temperature", and "Traffic Condition" itself. It takes more than two weeks observation to collect this information.

Along with the prediction of the traffic condition, other attributes that are needed in RCV calculation are also gathered. Since some attributes are dynamically change over time (i.e., weather information, heterogeneity, and average speed), the system must collect its latest values from several complementary sources (OpenWeather, CCTV, and TomTom digital map). Meanwhile, the remaining (road infrastructures) already determined since it has static values. These attributes define the RCV for each road segment. 


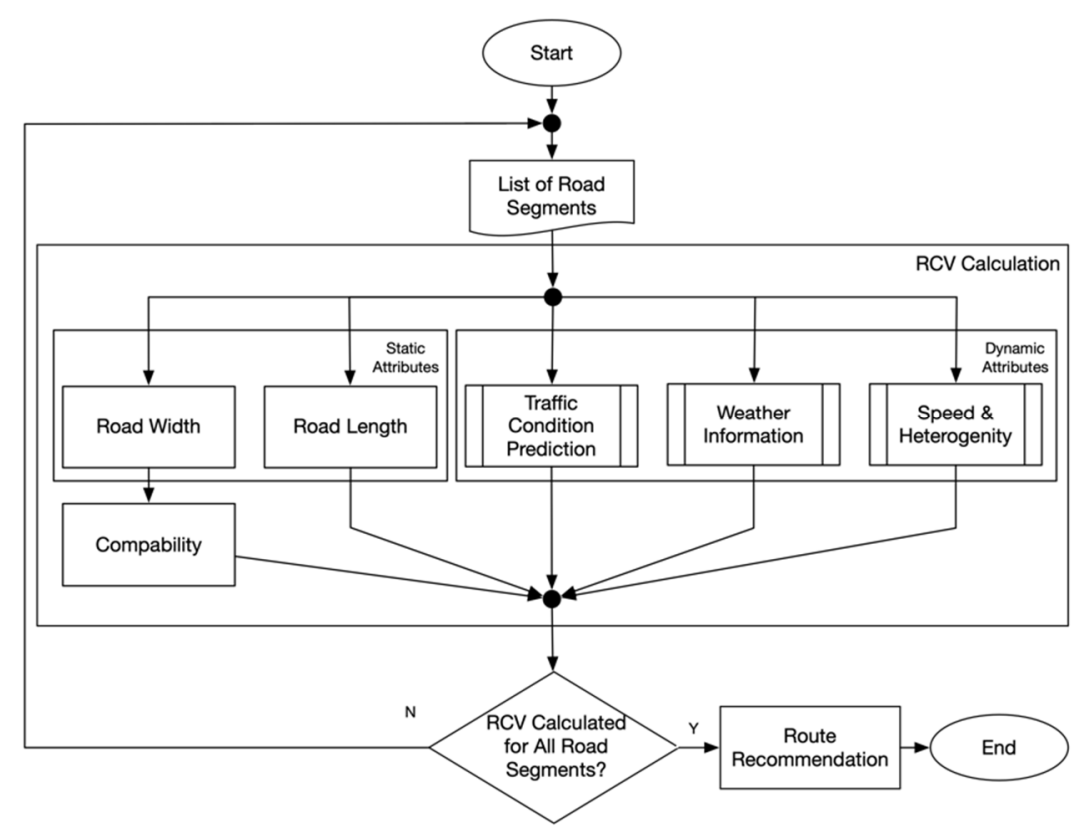

Figure 2. Proposed Framework.

The RCV calculation begins after the condition of traffic is predicted and the remaining attributes is collected. The attributes will have a priority level for determine which attribute has the biggest impact to drivers, so later drivers could have the most convenience route to themselves. Later, drivers can adjust its level as their driving preferences. However, in this research, the priority level for the attributes already determined based on the vehicle type (cars and motorcycles). The measurement of RCV for every road segments is using Multi Criteria Decision Making (MCDM) [55].

After the RCV determination for each road segment is complete, the system will continue to generate the recommended route. Its calculation is done by implementing Dijkstra Shortest Path Algorithm which tried to find the minimum sum of RCV from a pair of source and destination. The recommended route will be delivered to drivers in the form of the set of suggested paths.

\subsection{RCV Calculation}

The RCV calculation works based on MCDM method which requires levels of priority to create its final decision [56]. Its value is measured by collaborating several attributes such as road length, prediction of traffic condition, weather, temperature, humidity, average vehicle speed, heterogeneity, and compatibility. Table 2 shows the list of RCV attributes with its data range and characteristics which are used to determining the RCV.

Table 2. RCV Attributes, Data Range, and Characteristics of RCV.

\begin{tabular}{cccc}
\hline No & Attributes & Data Range & Characteristic \\
\hline 1 & Road Length & $0-1000$ & Non-Beneficial \\
2 & Traffic Condition & $0, \ldots, 3$ & Non-Beneficial \\
3 & Weather & Sunny, $\ldots$, Heavy Rain & Non-Beneficial \\
4 & Temperature & $0-100$ & Non-Beneficial \\
5 & Humidity & $0-100$ & Non-Beneficial \\
6 & Average Vehicle Speed & $0-100$ & Beneficial \\
7 & Heterogeneity & $0, \ldots, 3$ & Non-Beneficial \\
8 & Compatibility & $0 / 10$ & - \\
\hline
\end{tabular}

There are two types of attributes, namely static and dynamic attributes. Static attributes have fixed value, and it cannot change easily over time. In this paper, the static 
attribute is road infrastructure which covered information of road segment (junction location and road connectivity) and the length and width of the road. These attributes are manually gathered and measured using Google Maps for each road segments. Since the type of this attribute will not change in the short time, these data are stored in local database. The usage of road width attribute is for defining the suitability between the size of vehicle and the road.

On the other hand, dynamic attributes could be changed periodically over time. The collection of this attributes is gathered periodically before the process of RCV calculation begin. In this paper, we use prediction of traffic condition, weather condition, average speed of vehicle, and heterogeneity as the dynamic attributes.

\subsubsection{Compatibility}

The compatibility value is the last attribute that needed to calculate the RCV. The value of this attribute is based on the width of the road and the size of vehicles. Its range are only limited to 0 or 10 . If the width of the road exceeds the vehicle width, the compatibility value will be set into 10 , otherwise it will be set as 0 .

$$
\text { Compatibility }=\left\{\begin{array}{c}
10, \text { Road Width }>\text { Vehicle Width } \\
0, \text { Road Width }<\text { Vehicle Width }
\end{array}\right.
$$

Equation (1) is used to define the value of the compatibility. Both attributes have static value; the road width is manually measured, and the vehicle width is set 1.6 and $0.76 \mathrm{~m}$ for cars and motorcycles. Based on this calculation, the capability of a vehicle to passing a road is defined.

\subsubsection{Prediction of Traffic Condition}

The traffic condition is predicted based on each observed road segment dataset, which consists of several attributes such as, "days of week" $(D)$, "rush hour" $(R)$, "weather" $(W)$, "temperature" (Temp), and "traffic condition" $(T)$. This part is delivering the prediction of traffic condition $(T)$. It is based on a dataset from more than two weeks observation on 256 road segments. The classification of traffic condition covers four classes, which described the situation on the roads, namely: 0 (Uncongested), 1 (Moderate Traffic), 2 (Partially Congested), and 3 (Fully Congested).

The condition of traffic always changes over time. In order to predict the traffic, the chosen method must be capable to handle the traffic condition characteristic. Knowledge Growing Bayes Classifier is the most appropriate method that could be used to predict the road situation. Based on Husni et al., this method has the fastest prediction time among others [23], so it can be used to adapt with the current situation. It not only has the fastest prediction time, but also has the best performance gain when using the growing dataset between other methods. It needs attributes $T, D, R, W$, and Temp to predict the traffic condition. By using Equation (2), probability for each category (class) of traffic condition is calculated [11]. However, this equation is not considering the time aspect.

$$
P_{(T \mid D, R, W, \text { Temp })}=\frac{P_{(T, D, R, W, T e m p)}}{P_{(D, R, W, T e m p)}}
$$

To handle the time aspect, the implementation of Equation (3) could be used to find its probability for each class at time $(t)$. Meanwhile, Equation (4) is exemplifying the process of dataset growth for attribute days $(D)$. This equation is not only limited to this attribute, but also it applied to others. In the beginning $(t=0)$, the data training of attribute $D$ has same amount with the initial dataset, and when $t>0$ the data training of $D$ is extended 
with the current data testing of attribute $D$. This process is applied whenever the traffic condition is predicted and it made value of each attribute changed overtime [23].

$$
\begin{gathered}
P_{\left(T_{t} \mid D_{t}=a, \ldots, \text { Temp }_{t}=d\right)}=\frac{P_{\left(T_{t}=i, D_{t}=a, R_{t}=b, W_{t}=c, \text { Temp }_{t}=d\right)}}{P_{\left(D_{t}=a, R_{t}=b, W_{t}=c, \text { Temp }_{t}=d\right)}} \\
D_{t}=\left\{\begin{array}{l}
t=0, D_{t}=D_{\text {training }} \\
t>0 \ldots n, D_{t-1}+D_{t}
\end{array}\right.
\end{gathered}
$$

The prediction result is taken from the highest probability among all the categories in the certain $(t)$ time. It is calculated by using Equation (5) and decides the highest probability between traffic condition classes (i) for specified condition of attributes (i.e., $D_{t}=a, R_{t}=b$, $W_{t}=c$, and Tempt $=d$ ).

$$
\text { Traffic Condition }=\underset{T}{\arg \max } P_{t}\left(T_{i} \mid D_{t}=a, \ldots, \quad \operatorname{Temp}_{t}=d\right)
$$

\subsubsection{Weather, Average Vehicle's Speed, and Heterogeneity}

The values of weather condition, vehicle speed, and heterogeneity are gathered independently before the process of RCV calculation. Weather information (weather, temperature, and humidity) is gathered from OpenWeather, and both of average vehicle speed and heterogeneity attributes is obtained from public CCTV or TomTom digital maps.

The condition of weathers is limited to nine type of weather that commonly occur in Indonesia. Indonesia is in the equator, and it makes Indonesia only have two seasons (dry and rainy seasons). Its condition will be categorized into: (1) "clear sky"; (2) "few clouds"; (3) "scattered clouds"; (4) "broken clouds"; (5) "overcast clouds"; (6) "light rain"; (7) "moderate rain"; (8) "heavy intensity rain"; and (9) "very heavy rain". Later these conditions will be converted to numerical form to show the weather level (1 shows the best weather condition, and 9 shows the worst condition).

On the road segments that covered with public CCTV, the value of average vehicle speed and heterogeneity calculated using object detection and tracking from its streams. Measurement of average vehicle speed is done by counting the distance of movement of object between two frames based on Euclidian distance [57]. The following equations are used to determine the average vehicle's current speed on the observed road.

$$
\begin{gathered}
\text { Movement Distance }(p x)=\sqrt{\left(x_{1}-x_{2}\right)^{2}+\left(y_{1}-y_{2}\right)^{2}} \\
\text { Movement Distance }(m)=\frac{\text { Vehicle Length }(m) \times \text { Movement Distance }(p x)}{\text { Vehicle Length }(p x)} \\
\text { Vehicle Speed }\left(\frac{m}{s}\right)=\frac{\text { Movement Distance }(m)}{\text { Time }(s)} \times \frac{\text { FPS }}{\text { Frame Sampling }}
\end{gathered}
$$

The distance (in pixels) of every detected vehicle's position in the nearest two-frame in sequence, called $\left(x_{1}, y_{1}\right)$ and $\left(x_{1}, y_{2}\right)$, measured using Equation (6). Equation (7) converts its distance from pixels to meters. In the end, by combining the movement distance (in meters) with observation time, the value of FPS, and frame sampling, the vehicle speed is defined using Equation (8). At the same time, the speed for all vehicles that are detected in the CCTV streams is obtained, the determination of average vehicle speed begins. This process is applied for every observed road segments.

The usage of object detection method in CCTV streams is not only for measuring the vehicle speed, but also for calculating the variances of the vehicle on the road. The heterogeneity is measured based on the variances of the vehicle using Equation (9). The heterogeneity value is assigned to 0 , when there is only one type of light vehicle (cars or motorcycles) that detected from CCTV streams. This value will increase to 1 when the 
system detects both of this type of vehicles pass the roads. Meanwhile, the other values ( 2 or 3 ) are used if there are heavy vehicle (bus or/and truck) on the roads.

$$
\text { Heterogeneity }= \begin{cases}1, & \mid \text { Car or Motorcycle } \\ 2, & \mid \text { Car and Motorcycle } \\ 3, & \mid \text { Car and Motorcycle and (Bus or Truck) } \\ 4, & \mid \text { Car and Motorcycle and Bus or Truck }\end{cases}
$$

However, the coverage of public CCTV is limited to main road. In order to gather the average vehicle speed value on the other road that is not covered by CCTV, the complementary source for collecting this information is needed. It is collected by using TomTom digital maps which covers average speed on the roads. Therefore, the heterogeneity value on this road is assigned to 1 since its usage only for motorcycle.

As the attributes collection process is done, the RCV calculation continues. Collected attributes have its own characteristic, as seen in Table 2. It's called beneficial and non-beneficial characteristics. The attributes for calculating RCV are dominated by nonbeneficial characteristics, except for the vehicle speed. These characteristics give effect in the attribute normalization process. The attribute with non-beneficial characteristic delivers greater normalized value if the original value is smaller. On the other hand, the normalized value for beneficial attributes will increasing along the rise of the original attribute's value.

Each attribute must be pre-processed first by implementing normalization steps to unify the range of its value. In this research, the method that used to unify its range is Min-Max Normalization. Equation (10) is showing the proses to find the normalized value based on its characteristics [58,59].

$$
A_{i}^{\prime}=\left\{\begin{array}{c|l}
\frac{A_{i}-A^{\min }}{A^{\max }-A_{\min }}, & \text { Beneficial } \\
\frac{A^{\max }-A_{i}}{A^{\max }-A^{\min }}, & \text { Non }- \text { Beneficial }
\end{array}\right.
$$

This equation is used to define the $i$-th value of normalized attribute $\left(A_{i}^{\prime}\right)$ based on the value of $i$-th attribute $\left(A_{i}\right)$ and its highest and lowest value of attributes $\left(A^{\text {max }}\right.$ and $\left.A^{\text {min }}\right)$. The first part of equation is used for the beneficial attributes, meanwhile the second one is used for attributes with non-beneficial characteristic.

By the time all attributes are normalized, the priority level is assigned to each one. The level of priority is given because the system should understand what the order of importance to the attributes for the drivers. Equation (11) is used to find the final value of RCV for each observed road segment. By combining the normalized attributes $\left(X_{i}^{\prime}\right)$ and its priority level ratio $\left(C_{i}\right)$, the RCV is calculated.

$$
R C V_{i}=\sum_{i=1}^{n} C_{i} A_{i}^{\prime}
$$

Table 3 shows the attributes order; from the highest (1) to the lowest (7), based on its priority level and its ratio. There is a differentiation between cars and motorcycles since each vehicle has its own characteristics (physical form, driving style, etc.). Based on motorcycles physical form, it cannot protect the driver from the weather conditions (weather and temperature), so these attributes must have the highest priority. On the other hand, the physical form of a car covers its passenger from weather, and it makes these attributes assigned as the lowest priority.

A motorcycle also has a maneuver capability when it runs on the roads, and it has less difficulties in facing the variances of vehicle, so therefore the heterogeneity is set as the lowest priority. Meanwhile, traffic condition and heterogeneity are the highest priority because cars can be got stuck in traffic, but it cannot hinder the traffic easily by maneuvering as motorcycles. The arrangement of priority level could be customized as driver's preferences. However, in this research, the variance of preferences is limited only by the type of vehicles. 
Table 3. Priority Level of Attributes and Its Ratio.

\begin{tabular}{cccc}
\hline Priority Level & $\begin{array}{c}\text { Attributes } \\
\left(\text { Car) }\left(\boldsymbol{A}_{\boldsymbol{i}}^{\prime}\right)\right.\end{array}$ & $\begin{array}{c}\text { Attributes } \\
\text { (Motorcycle) }\left(\boldsymbol{A}_{\boldsymbol{i}}^{\prime}\right)\end{array}$ & $\begin{array}{c}\text { Ratio } \\
\left(\boldsymbol{C}_{\boldsymbol{i}}\right)\end{array}$ \\
\hline 1 & Traffic Condition & Weather & $25 \%$ \\
2 & Heterogeneity & Temperature & $21 \%$ \\
3 & Current Speed & Traffic Condition & $18 \%$ \\
4 & Road Length & Current Speed & $14 \%$ \\
5 & Temperature & Road Length & $11 \%$ \\
6 & Weather & Humidity & $7 \%$ \\
7 & Humidity & Heterogeneity & $4 \%$ \\
\hline
\end{tabular}

The ratio is complied with the order of priority level. The ratio's value illustrates how much the attributes will affect the RCV. The summation of ratio's value must be equal to 1 , so each attribute must take its portion based on the priority level. Equation (12) is an expansion of previous equation that include the ratio value for each attribute. The compatibility value does not contribute to attribute with priority level since it acts as a regularizer to fit between the width of the road and the vehicle size.

$$
R C V=\left(25 \% \times A_{1}^{\prime}\right)+\left(21 \% \times A_{2}^{\prime}\right)+\left(18 \% \times A_{3}^{\prime}\right)+\left(14 \% \times A_{4}^{\prime}\right)+\left(11 \% \times A_{5}^{\prime}\right)+\left(7 \% \times A_{6}^{\prime}\right)+\left(4 \% \times A_{7}^{\prime}\right)+\operatorname{Comp}
$$

\subsection{Route Recommendation}

The recommendation of a route is affected by RCV calculation from each road segment. $\mathrm{RCV}$ is used as inputs in recommendation system. By implementing the Dijkstra algorithm, the route from a specified source and destination is calculated. Each node is connected at least with one edge in the form of matrices (connected nodes, road information, and RCV). The route which has the minimum sum of RCV is considered as the best route for drivers. Equation (13) is used for finding the recommended route from a pair of designated source and destination [60].

$$
\text { Route }=\min \sum_{i=s r c}^{d s t} R C V_{i}
$$

The result of route calculation is in the form of path list between nodes. In this research, the route is shown in a graph from a designated source and destination. It also shows the compatibility of route that chosen with the width of vehicle. The route recommendation between cars and motorcycles are different. A car is unable to use the alternative route that only designated for motorcycles, since its width exceeds the road width, otherwise motorcycles can choose every route on the maps (even it is not the recommendation route).

Based on the RCV of each road segment, the best route will be determined by using Dijkstra shortest path algorithm. The suggested route will find the minimum sum of $\mathrm{RCV}$ from the designated source and destination. In the end, the recommended route not only considers the suitability between road width and vehicle size, but also the driver's preferences.

\section{Results and Discussions}

The observation area in this research is conducted around R.E. Martadinata, Bandung, Indonesia. Figure 3 shows the area that observed in this paper. In the red-colored road segment, it refers to the roads that can be passed by any type of vehicles, meanwhile the blue-colored one represents to the road that specified only for motorcycles and it can be used as alternative routes for motorcycles. The observation of these road segments is conducted independently for RCV calculation. 


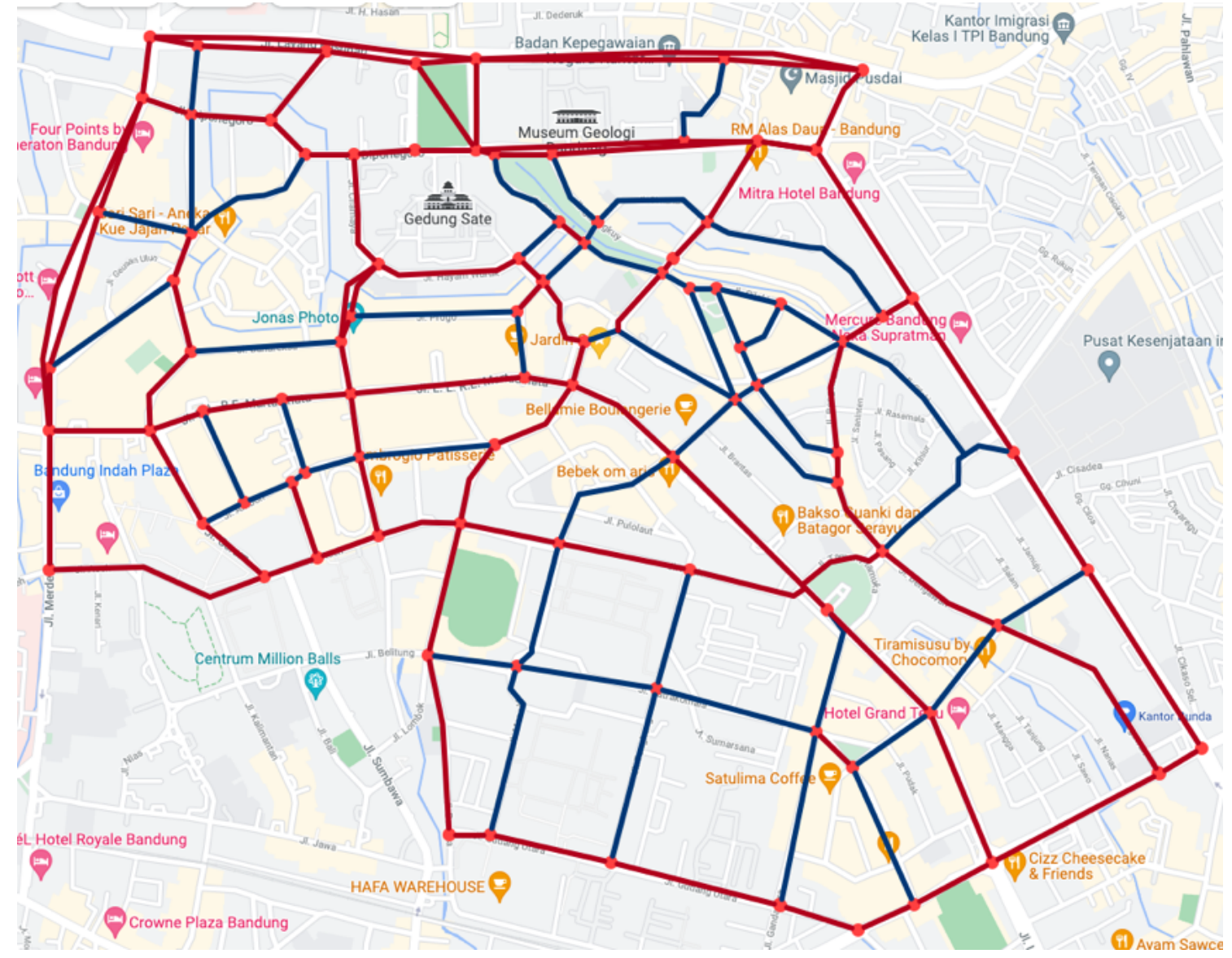

Figure 3. Observed Area.

\subsection{Prediction System of Traffic Condition}

Based on the traffic condition dataset, it turns out that the data is imbalanced between classes. The "Uncongested" traffic condition dominates the dataset for all road segments. To handle the imbalanced data, it must be re-sampled using Synthetic Minority Oversampling Technique (SMOTE) [23,61,62].

The prediction of the traffic condition begins immediately after the dataset is balanced between its classes. The attributes of the traffic condition prediction are days, rush hour, weather, and temperature. This system runs independently for each observed road segment in order to make the faster prediction time. Its result determines the traffic condition which has same situation with current condition.

Performance testing is conducted for every observed road segment. It is done to know the quality of prediction system. The measured performances are limited to accuracy, precision, and recall. Validation process also implemented to the testing using 4-fold validation. Dataset is divided into four partitions (A, B, C, and D), of which three of its partitions are used as training data and the remaining is used as testing data. It is done by using the combination of training and testing data as seen in Table 4.

Table 4. Cross Validation Scheme on Predicting Traffic Condition.

\begin{tabular}{ccc}
\hline No & Training Data & Testing Data \\
\hline 1 & A, B, C & D \\
2 & B, C, D & A \\
3 & A, C, D & B \\
4 & A, B, D & C \\
\hline
\end{tabular}


Based on the concept of knowledge growth, every time the system predicts a traffic condition, the current dataset will be added to with its prediction results and other traffic attributes. In this paper, we applied the knowledge growing concept on Bayes Classifier, Decision Tree, and Deep Neural Network to predict current traffic condition. Based on the testing results, Knowledge Growing Bayes Classifier method has better performances gain among others (Decision Tree and Deep Neural Network modified with Knowledge Growing concept).

Table 5 shows the comparison of testing results between prediction methods. This test is conducted on a road segment ("Lombok - Pramuka"). The difference between scheme (a) and (b) is the amount of data that is used to predict the traffic condition. Initially, both schemes used $50 \%$ of the dataset as data training. In scheme (a), the testing data used only $25 \%$ of the dataset (50\% training and $25 \%$ testing). Meanwhile in scheme (b), there will be additional testing data from the rest of the unused dataset (50\% training, $25 \%$ testing, and $25 \%$ additional testing data).

Table 5. Comparison of Prediction Method using Knowledge Growing.

\begin{tabular}{ccccc}
\hline Methods & Accuracy (\%) & Precision (\%) & Recall (\%) & Processing Time (s) \\
\hline KG-Bayes Classifier (a) & 68.06 & 70.61 & 68.06 & 0.06 \\
KG-Bayes Classifier (b) & 70.05 & 71.77 & 70.05 & 0.12 \\
KG-Deep Neural Network (a) & 68.36 & 69.51 & 68.36 & 571.03 \\
KG-Deep Neural Network (b) & 68.96 & 69.72 & 68.96 & 1434.02 \\
KG-Decision Tree (a) & 78.51 & 78.85 & 78.51 & 2.30 \\
KG-Decision Tree (b) & 79.44 & 79.72 & 79.44 & 5.83 \\
\hline
\end{tabular}

It can also be seen in Table 5; the accuracy of Knowledge Growing Bayes Classifier is rising 1.99 point (from $68.06 \%$ to $70.05 \%$ ) and its precision is also rising from $70.61 \%$ to $71.77 \%$ (1.16 point). The other methods also have better performances when the training data grows, but it's just not as good as Knowledge Growing Bayes Classifier. Growing knowledge in Decision Tree and Deep Neural Network make its accuracy rose around 0.94 point $(78.51 \%$ to $79.44 \%)$ and 0.6 point $(68.36 \%$ to $68.96 \%)$, meanwhile its precision rose from $78.75 \%$ to $79.72 \%$ ( 0.87 point) and from $69.51 \%$ to. $69.72 \%$ ( 0.22 point). The value of recall is similar with its accuracy, this occurred since each class is already balanced and the system is able to classify the positive and negative classes equally $(P=N)$. Figure 4 shows the performance comparison between these three methods.

Apart from having the biggest gain in performance between testing schemes, Knowledge Growing Bayes Classifier also has the quickest time processing among all methods, which has less than $1 \mathrm{~s}$ for all schemes that were tested. Decision Tree needs a longer amount of time to process the dataset when the training data grows, it takes 2.3 and $5.83 \mathrm{~s}$ for scheme (a) and (b), respectively. Meanwhile Knowledge Growing Deep Neural Network has the longest time processing in predicting the dataset. The growth of data training made this method must re-learn the network for predicting the traffic condition. When implementing the first scheme, it takes more than $500 \mathrm{~s}$ to predict the traffic condition in this road segment, and it takes more than $1400 \mathrm{~s}$ when processing the dataset using the scheme (b). Based on these performance tests, the Knowledge Growing Bayes Classifier is used to handle the prediction of traffic condition on other road segments.

Figure 5 is the result of performance testing on several observed road segment. Overall, the lowest accuracy is appeared in "Juanda-Trunojoyo" $(60.78 \%)$, meanwhile the highest accuracy is in "Trunojoyo-Banda" (73.69\%). For its precision, the highest and lowest values appear in "Trunojoyo-Banda" (77.39\%) and "Juanda-Trunojoyo" (63.64\%) respectively. The performance result of traffic condition prediction is shown in Table 6. Its result is used as traffic condition's attribute when calculating RCV. 


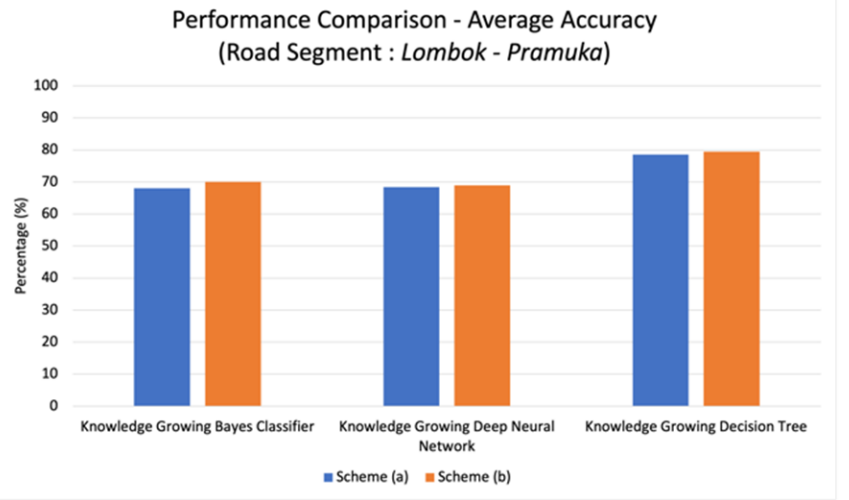

(a)

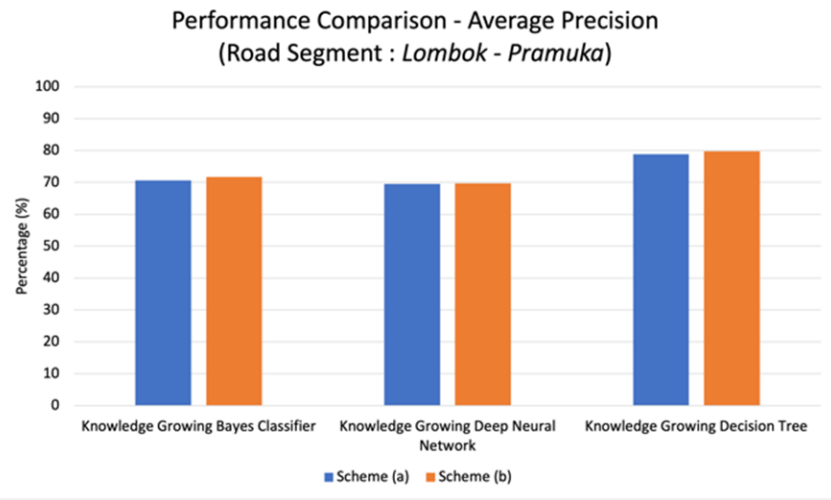

(b)

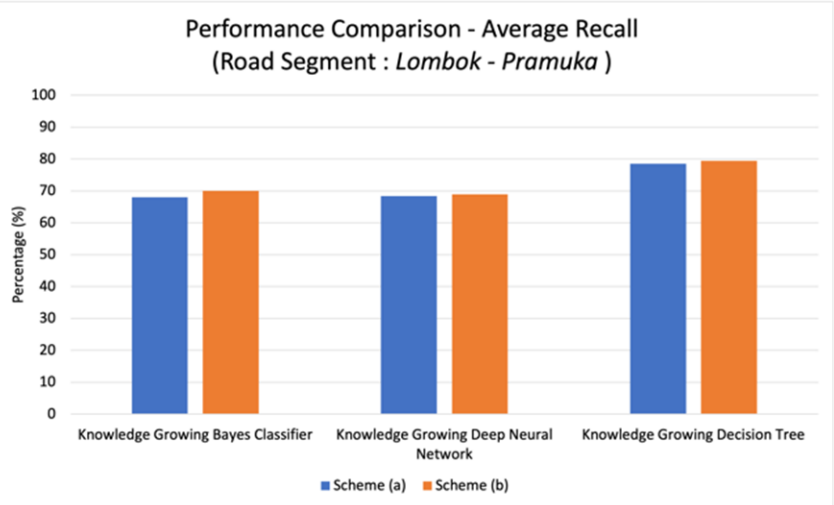

(c)

Figure 4. Performance Comparison Between KG-Bayes Classifier, KG-Deep Neural Network, and KG-Decision Tree in A Road Segment "Lombok-Pramuka": (a) Average Accuracy; (b) Average Precision; (c) Average Recall.

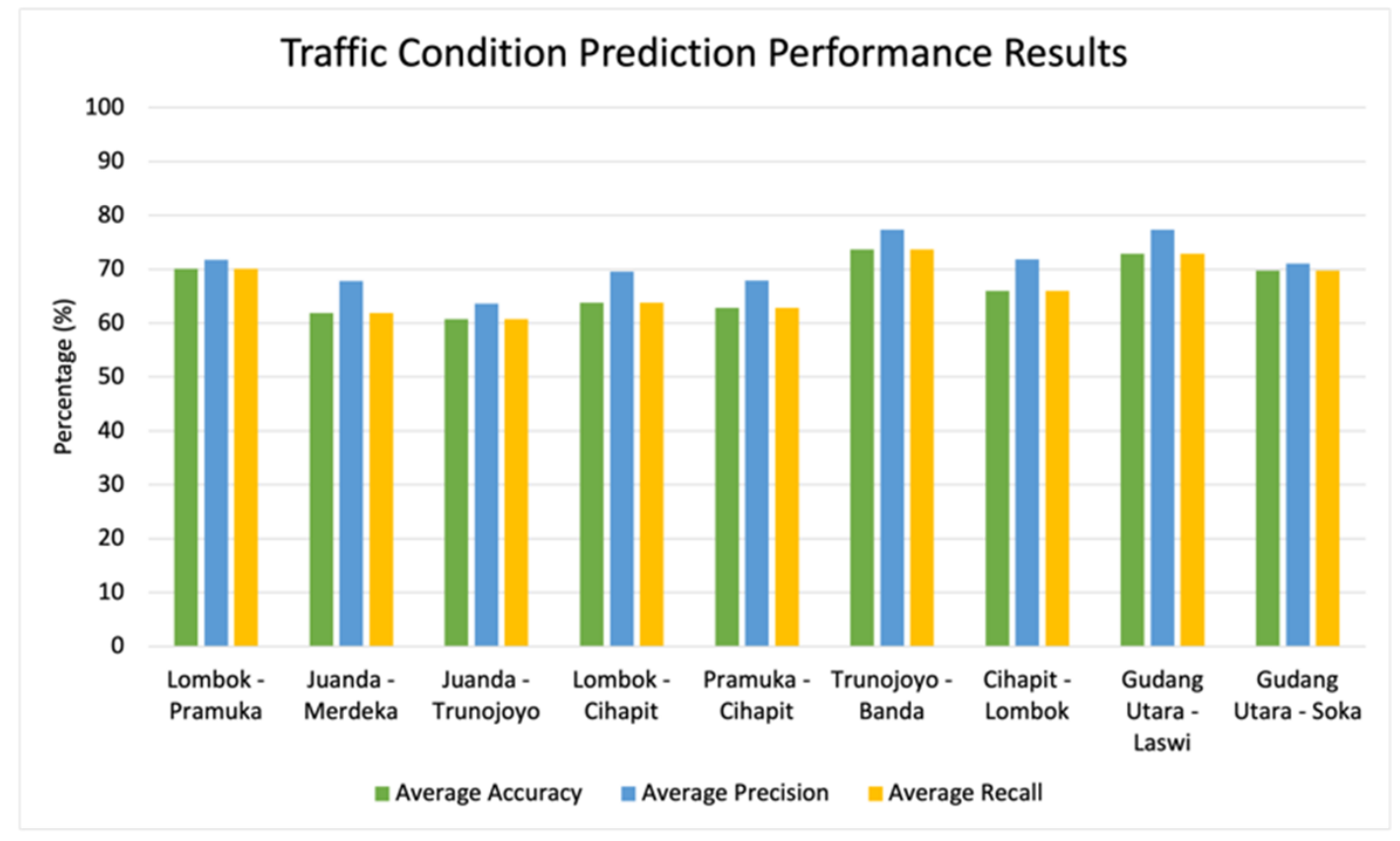

Figure 5. Performance Testing on Several Observed Location. 
Table 6. Average Accuracy and Precision on Prediction of Traffic Condition.

\begin{tabular}{cccc}
\hline Dataset & Average Accuracy (\%) & Average Precision (\%) & Average Recall (\%) \\
\hline Lombok-Pramuka & 70.05 & 71.77 & 70.05 \\
Juanda-Merdeka & 61.84 & 67.84 & 61.84 \\
Juanda-Trunojoyo & 60.78 & 63.64 & 60.78 \\
Lombok-Cihapit & 63.81 & 69.58 & 63.81 \\
Pramuka-Cihapit & 62.86 & 67.94 & 62.86 \\
Trunojoyo-Banda & 73.69 & 77.39 & 73.69 \\
Cihapit-Lombok & 66.00 & 71.82 & 66.00 \\
Gudang Utara-Laswi & 72.88 & 77.35 & 72.88 \\
Gudang Utara-Soka & 69.77 & 71.10 & 69.77 \\
\hline
\end{tabular}

\subsection{The Calculation of RCV}

In the beginning of the RCV calculation, several pieces of information such traffic condition, weather condition, vehicle type, and road infrastructure (road length and width) are collected. Hereafter, the system prepares this information so that it can be used as $\mathrm{RCV}$ attributes. It also calculates the compatibility value which described the suitability between the road and vehicle width. If the width of vehicle exceeds the road width, the compatibility is set to 10 , otherwise, it has 0 as the compatibility value.

Table 7 shows the raw data of RCV attributes which collected in the several selected road segments. The collection of $\mathrm{RCV}$ attributes is begin before the route recommendation process. It can be seen, there are some results where the vehicle's width exceeds the road width and its compatibility's value is set to 10. Compatibility is the only attribute that does not have a priority level. Meanwhile in Table 8, it shows the result of RCV calculation in the same selected road segments. It can be seen in the table, road segments "Trunojoyo-Banda" and "Seram-Saparua" had 10.54 and 10.74 as the RCV. This means that these road segments are unsuitable for the vehicle type. Meanwhile, in other road is compatible with the type of vehicle since the compatibility is set to 0 , and it gives the result of RCV calculation between 0.33 to 0.59 .

Table 7. Raw Data of RCV Attributes.

\begin{tabular}{ccccccccccc}
\hline Source & Destination & $\begin{array}{c}\text { Vehicle } \\
\text { Type }\end{array}$ & $\begin{array}{c}\text { Traffic } \\
\text { Condition }\end{array}$ & $\begin{array}{c}\text { Weather } \\
\text { Condition }\end{array}$ & Temperature & Humidity & Heterogeneity & $\begin{array}{c}\text { Current } \\
\text { Speed }\end{array}$ & $\begin{array}{c}\text { Road } \\
\text { Length }\end{array}$ & Compatibility \\
\hline Cihapit & Banda & Car & 0 & $\begin{array}{c}\text { Overcast } \\
\text { clouds }\end{array}$ & 25.01 & 70 & 3 & 29 & 506 & 0 \\
Laswi & $\begin{array}{c}\text { Gudang } \\
\text { Utara }\end{array}$ & Car & 0 & $\begin{array}{c}\text { Overcast } \\
\text { clouds }\end{array}$ & 25.16 & 70 & 1 & 34 & 532 & 10 \\
Trunojoyo & Banda & Car & 0 & $\begin{array}{c}\text { Overcast } \\
\text { clouds }\end{array}$ & 24.99 & 70 & 3 & 25 & 446 & 0 \\
Seram_0 & Saparua_0 & Car & 2 & $\begin{array}{c}\text { Overcast } \\
\text { clouds }\end{array}$ & 25.01 & 70 & 1 & 27 & 273 & 10 \\
Pramuka & Lombok & Motorcycles & 0 & $\begin{array}{c}\text { Overcast } \\
\text { clouds }\end{array}$ & 25.01 & 70 & 1 & 36 & 877 & 0 \\
Cihapit & Pramuka & Motorcycles & 0 & $\begin{array}{c}\text { Overcast } \\
\text { clouds }\end{array}$ & 25.01 & 70 & 3 & 29 & 777 & 0 \\
Pramuka & Anggrek & Motorcycles & 0 & $\begin{array}{c}\text { Overcast } \\
\text { clouds }\end{array}$ & 25.1 & 70 & 4 & 29 & 320 & 0 \\
Seram_0 & Saparua_0 & Motorcycles & 2 & $\begin{array}{c}\text { Overcast } \\
\text { clouds }\end{array}$ & 25.01 & 70 & 1 & 27 & 273 \\
\hline
\end{tabular}

Table 8. Calculation Result of RCV in Road Segments.

\begin{tabular}{|c|c|c|c|c|c|c|c|c|c|c|c|}
\hline Source & Destination & Vehicle Type & $\begin{array}{c}\text { Traffic } \\
\text { Condition }\end{array}$ & $\begin{array}{l}\text { Weather } \\
\text { Condition }\end{array}$ & Temperature & Humidity & Heterogeneity & Travel Time & Road Length & Compatibility & RCV \\
\hline Cihapit & Banda & Car & 0 & 0.5 & 0.25 & 0.5 & 0 & 0.99 & 0.49 & 0 & 0.33 \\
\hline Laswi & Gudang Utara & $\mathrm{Car}$ & 0 & 0.5 & 0.252 & 0.5 & 1 & 0.99 & 0.47 & 10 & 10.54 \\
\hline Trunojoyo & Banda & Car & 0 & 0.5 & 0.25 & 0.5 & 0.33 & 0.99 & 0.55 & 0 & 0.41 \\
\hline Seram_0 & Saparua_0 & $\mathrm{Car}$ & 0.667 & 0.5 & 0.25 & 0.5 & 1 & 1 & 0.73 & 10 & 10.74 \\
\hline Pramuka & Lombok & Motorcycles & 0 & 0.5 & 0.25 & 0.5 & 1 & 0.99 & 0.12 & 0 & 0.4 \\
\hline Cihapit & Pramuka & Motorcycles & 0 & 0.5 & 0.25 & 0.5 & 1 & 0.99 & 0.22 & 0 & 0.42 \\
\hline Pramuka & Anggrek & Motorcycles & 0 & 0.5 & 0.251 & 0.5 & 0.33 & 1 & 0.68 & 0 & 0.44 \\
\hline Seram_0 & Saparua_0 & Motorcycles & 0.667 & 0.5 & 0.25 & 0.5 & 1 & 1 & 0.73 & 0 & 0.59 \\
\hline
\end{tabular}


The value of heterogeneity and average vehicle speed are collected right before RCV calculation, so its value is the latest measurement value on each road. The heterogeneity value for main roads is gathered using object detection in public CCTV's streams. On the other hand, for roads without CCTV's coverage, its value is set as 0 since the vehicles on this road are limited to motorcycles, and thus the traffic is homogeneous. The average vehicle speed attribute is collected using TomTom digital maps. The calculation of RCV begins after these two attributes are obtained.

\subsection{Route Recommendation}

Based on the RCV calculation on each road segment, the best path from a source to a destination is determined. RCV calculation and route recommendation run using python 3.7 and work based on networkx library for implementing the Djikstra shortest path algorithm (networkx.algorithms.shortestpaths.generic.shortestpath). There will be several simulations in order to find the result of recommended route: (1) generation the route recommendation within the distance variances of source and destination, and (2) comparation of route between the proposed RCV and common attributes (travel distance, time travel, and traffic condition).

\subsubsection{Simulation of Recommended Route Based on Variances of Travel Distance}

The simulation of route recommendation is done to several distance schemes (short and long distance). The short-distance route simulation covers around $3000 \mathrm{~m}$ road length, meanwhile the long-distance covers around $3500 \mathrm{~m}$. The short-distance simulation will have "Merdeka-Gudang Utara" and "Juanda-Laswi" as its pairs of source and destination. On the other hand, the long-distance simulation calculates the recommended routes from "AhmadYani" to "Juanda_2" and from "Bengawan_1" to "SimpangBCA". Table 9 shows the route from the simulation with different distance schemes.

Table 9. Simulation Result of Route Recommendation Based on The Distance Variances for A Vehicle (Motorcycles).

\begin{tabular}{|c|c|c|c|c|}
\hline Source & Destination & $\begin{array}{l}\text { Distance } \\
\text { Schemes }\end{array}$ & $\begin{array}{l}\text { Distance } \\
\text { (Meters) }\end{array}$ & Routes \\
\hline Merdeka & GudangUtara & Short Distance & 2449 & $\begin{array}{c}\text { Merdeka-Seram_0-Saparua_2-Saparua_0-LombokSelatan_1-Menado_2- } \\
\text { GudangUtara_4-GudangUtara_3-GudangUtara_2-GudangUtara }\end{array}$ \\
\hline Juanda & Laswi & Short Distance & 3099 & $\begin{array}{c}\text { Juanda-Merdeka-Seram_0-Saparua_2-Saparua_0-LombokSelatan_1-Aceh_2- } \\
\text { Cihapit-Pramuka-Anggrek_0-Laswi }\end{array}$ \\
\hline AhmadYani & Juanda_2 & Long Distance & 3624 & $\begin{array}{c}\text { AhmadYani-Supratman_3-Supratman_2-Supratman_1-Pusdai- } \\
\text { Diponegoro_7-Diponegoro_6-Diponegoro_5-Diponegoro_4-Cilamaya- } \\
\text { Trunojoyo_4-MaulanaYusuf_1-Juanda_2 }\end{array}$ \\
\hline Bengawan_1 & SimpangBCA & Long Distance & 3712 & $\begin{array}{c}\text { Bengawan_1-Bengawan_2-Bengawan_3-Supratman_2-Supratman_1-Pusdai- } \\
\text { Diponegoro_7-Diponegoro_6-Diponegoro_5-Surapati_1-AriaJipang_2- } \\
\text { Surapati_2-SimpangBCA }\end{array}$ \\
\hline
\end{tabular}

It can be seen in Figure 6, the recommended route is not only limited to one type of road. By using RCV, the route that chosen is the best path based on attributes that used. In Figure 6, the red and purple-coloured lines show the recommended route for short-distance trips "Merdeka-GudangUtara" and "Juanda-Laswi". Meanwhile, long-distance simulation results are shown in pink and orange-coloured line for trip "AhmadYani-Juanda_2" and "Bengawan_1-SimpangBCA" respectively.

Since the vehicle type in this simulation is allowed to use any type of roads, the usage of alternative paths is allowed in order to reach the destination. The alternative road is used in "Bengawan_1-SimpangBCA" trip, namely "Bengawan_3-Supratman_2" road segment. Based on the simulation, the system combines the usage of the main road and its alternatives, as long as it's compatible with the vehicle size. 


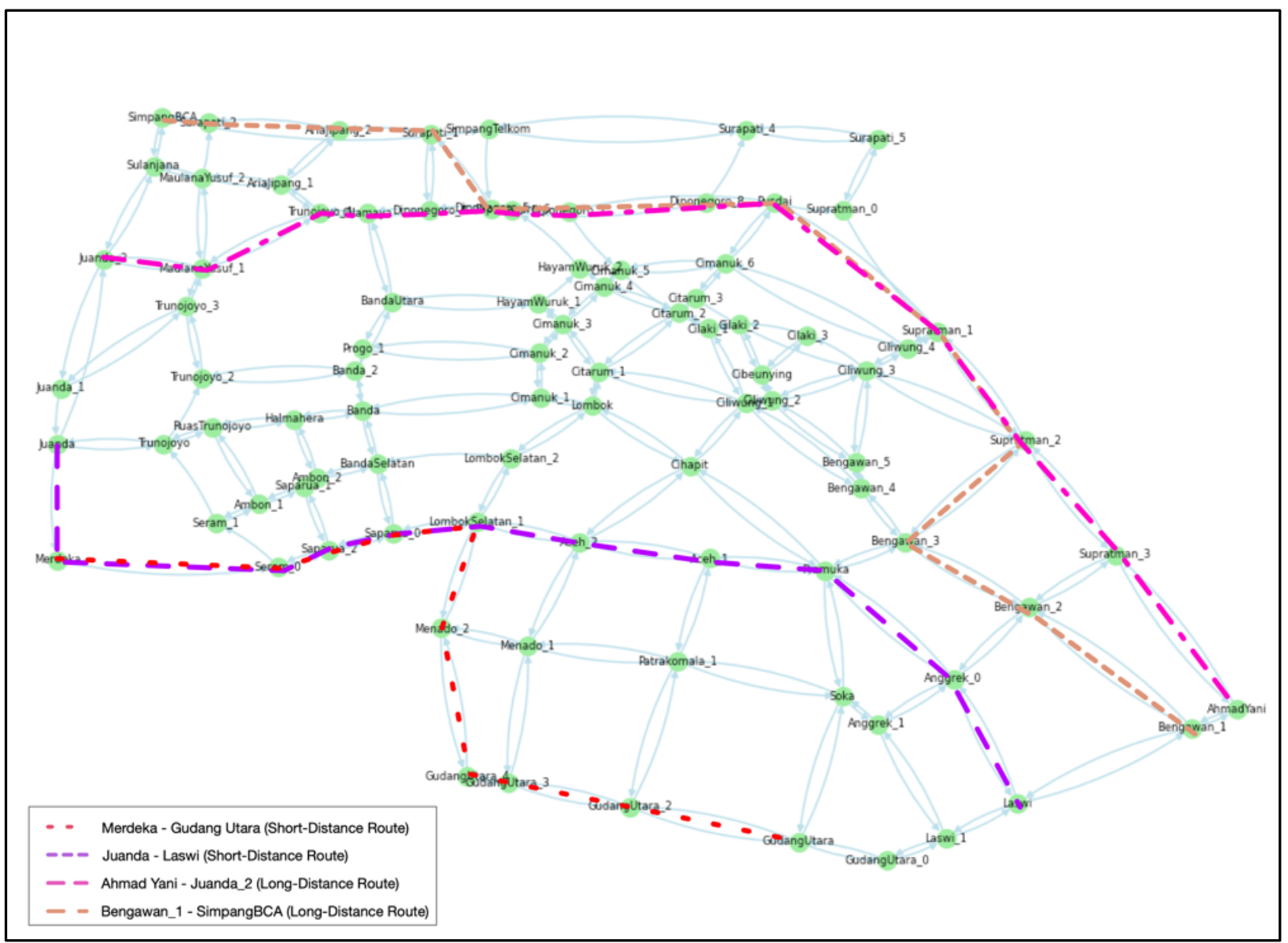

Figure 6. The Simulation Result of Route Recommendation with Various Distances.

\subsubsection{Comparison of Recommended Route Based on Variances of Attributes}

Generally, drivers select their route based simply road attributes, such as less traffic, shorter distance, or shorter travel time. Based on these conditions, the comparation between route recommendation based on RCV with other road attributes is done. Since the usage of alternative roads is limited to motorcycles, the variances of paths will be wider for motorcycles. Table 10 shows the comparison of recommended routes based on the road attribute measurements. The comparison delivers the best route based on RCV, traffic condition, travel distance, and travel time from "Juanda" to "Laswi".

Table 10. Simulation Result of Route Recommendation Based on The Attributes Measurements for Vehicles (Car and Motorcycle).

\begin{tabular}{|c|c|c|}
\hline Vehicle Type & Attributes Measurements & Routes \\
\hline Car & $\mathrm{RCV}$ & $\begin{array}{c}\text { Juanda-Merdeka-Seram_0-Saparua_2-Saparua_0-LombokSelatan_1-Aceh_2- } \\
\text { Aceh_1-Pramuka-Anggrek_0-Laswi }\end{array}$ \\
\hline Motorcycle & $\mathrm{RCV}$ & $\begin{array}{c}\text { Juanda-Trunojoyo-RuasTrunojoyo-Halmahera-Banda-Cimanuk_1-Lombok- } \\
\text { Cihapit-Pramuka-Anggrek_0-Laswi }\end{array}$ \\
\hline Car/Motorcycle & Travel Distance & $\begin{array}{c}\text { Juanda-Trunojoyo-RuasTrunojoyo-Halmahera-Banda-Cimanuk_1-Lombok- } \\
\text { Cihapit-Pramuka-Anggrek_0-Laswi }\end{array}$ \\
\hline Car/Motorcycle & Travel Time & $\begin{array}{c}\text { Juanda-Merdeka-Seram_0-Saparua_2-Saparua_0-LombokSelatan_1-Aceh_2- } \\
\text { Aceh_1-Pramuka-Anggrek_0-Laswi }\end{array}$ \\
\hline Car/Motorcycle & Traffic Condition & $\begin{array}{c}\text { Juanda-Juanda_2-MaulanaYusuf_1-Trunojoyo_4-Cilamaya-Diponegoro_4- } \\
\text { Diponegoro_5-Diponegoro_8-Pusdai-Supratman_0-Supratman_1- } \\
\text { Supratman_2-Bengawan_3-Pramuka-Anggrek_0-Laswi }\end{array}$ \\
\hline
\end{tabular}


As seen in Table 10, the routes that are suggested almost have the same path. When calculating the recommended route using RCV for cars, it suggests driving along the path "Juanda-Merdeka-Seram_0-Saparua_2-Saparua_0-LombokSelatan_1-Aceh_2-Aceh_1-PramukaAnggrek_0-Laswi". The route recommendation system delivers different paths when calculated using the RCV for motorcycles. The drivers should take path "Juanda-TrunojoyoRuasTrunojoyo-Halmahera-Banda-Cimanuk_1-Lombok-Cihapit-Pramuka-Anggrek_0-Laswi" to reach the destination. It appears that the system recommends the same routes when using Travel Distance Attributes. In order to save the travel time, drivers should pass the same route for cars based on RCV calculation.

At last, drivers should drove their vehicle away to avoid the traffic. By the time of simulation is conducted, the recommended route for avoiding the traffic is "Juanda-Juanda_2MaulanaYusuf_1-Trunojoyo_4-Cilamaya-Diponegoro_4-Diponegoro_5-Diponegoro_8-PusdaiSupratman_0-Supratman_1-Supratman_2-Bengawan_3-Pramuka-Anggrek_0-Laswi". All routes that compared in this simulation are illustrated in Figure 7.

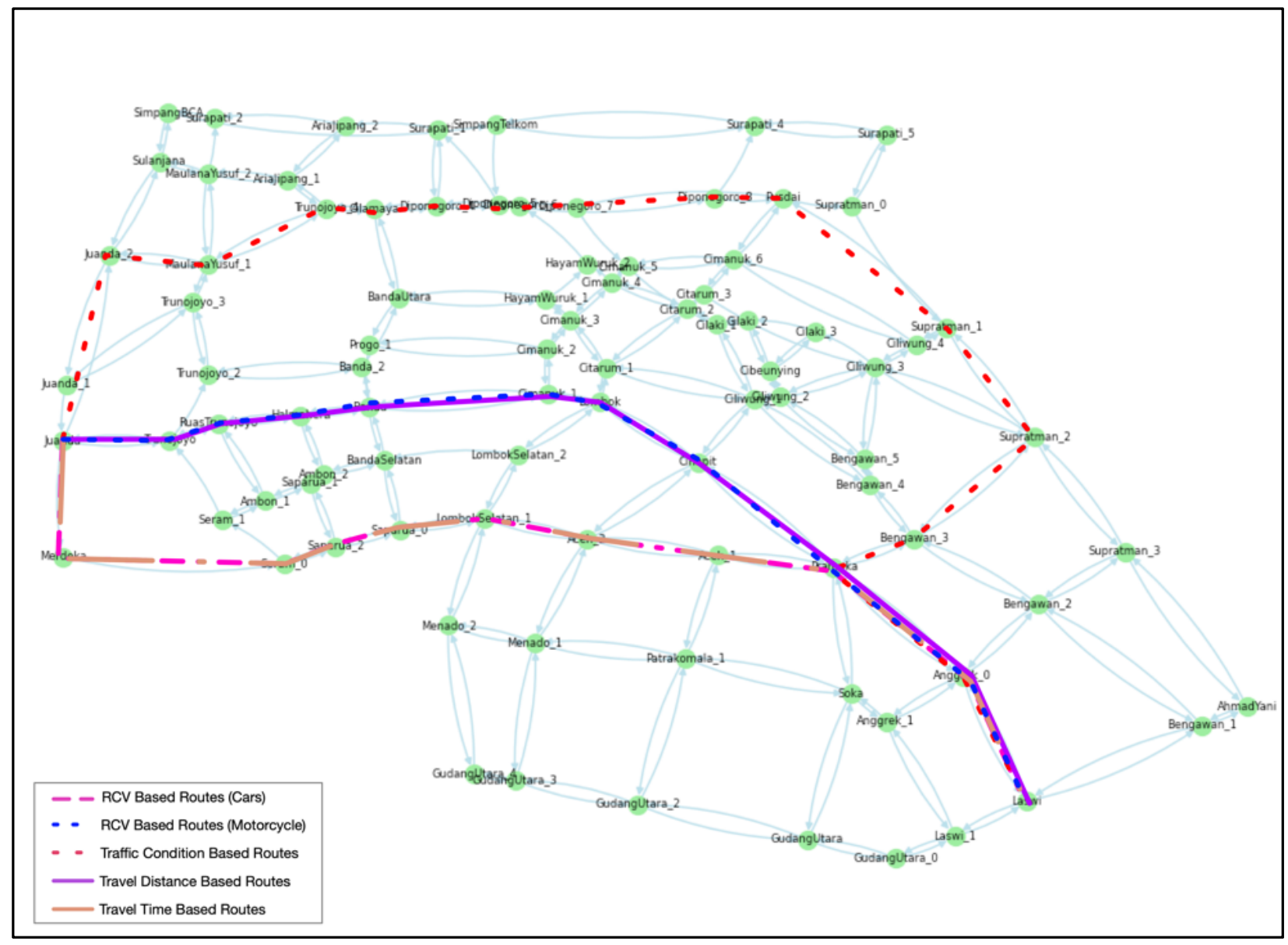

Figure 7. Recommended Route Comparison for Vehicles (Cars and Motorcycles) Based on Road Attributes.

The recommended routes might deliver same paths when calculated using each road attribute. The alternative roads only able to use by motorcycle since it has small size. Meanwhile, cars only will be suggested to use the main road instead the alternatives. When using RCV, there will be a compatibility value to define the suitability between vehicle and road width. Other methods could deliver the wrong path for certain types of vehicles. In this simulation, route recommendation based on travel distance and time could be used by any type of vehicle. However, the route based on traffic condition is not appropriate with cars, since it recommends the road segments "Juanda_2-MaulanaYusuf_1-Trunojoyo_4" which is intended for motorcycles only. 
Based on the compatibility value in RCV calculation, the recommendation route for car drivers is limited to the main road only. On the other hand, the suggestion for motorcycle's route will have several variances of alternate routes to reach the destination. The compatibility feature sets the final result of RCV, and it ensures the route can be passed by a vehicle. The compatibility will prevent big vehicles (car) from passing the route that is suggested.

\section{Conclusions}

This study proposed a framework for a route recommendation system by utilizing the traffic conditions and vehicle types. The routes that are delivered to the drivers will be calculated based on the collaboration of several attributes (prediction of traffic condition, weather condition, temperature, humidity, heterogeneity, speed, road length and compatibility). The collaboration of these attributes will generate the RCV as the situation of each road segment. The route that is recommended will be measured based on the minimum sum of RCV from a source to a destination.

The current traffic condition will be predicted by Knowledge-Growing Bayes Classifier, which has the greater performance gain and the fastest processing time among other methods that were tested. The results showed that the accuracy, precision, and recall of prediction for observed road segments are $60.78-73.69 \%, 63.64-77.39 \%$, and $60.78-73.69 \%$ respectively.

Attributes that affect the road capacity value are weather conditions (weather, temperature, and humidity), road infrastructures (road width and length), average travel speed, and heterogeneity. These attributes were aggregated in accordance with the priority level. In the end, the road capacity value was adjusted by considering the compatibility value to find the suitability between the road size and the vehicle types. The recommended route which is given to drivers is based on the minimum sum of RCV from every road segment determined based on the origin and destination information. Based on the simulation, the system always strongly recommends the car drivers to use the main road. On the other hand, the motorcycle driver could be suggested a greater variety of routes.

For further research, the improvement of road networks could be done to find more alternative path that can be passed for every kind of vehicle. Besides that, the variance of attributes that leads to road closure could also be added to the system, since this research only uses the basic attributes on transportation system.

Author Contributions: Conceptualization, S.M.N., E.H. and K.K.; methodology, S.M.N., E.H. and K.K.; software, S.M.N.; validation, S.M.N., R.Y. and B.N.Y.; formal analysis, S.M.N., E.H. and K.K.; investigation, S.M.N. and E.H.; resources, S.M.N. and E.H.; data curation, S.M.N. and E.H.; writingoriginal draft preparation, S.M.N.; writing—review and editing, S.M.N., E.H., R.Y. and B.N.Y.; visualization, S.M.N. and B.N.Y.; supervision, E.H., K.K., R.Y. and B.N.Y.; project administration, E.H. and S.M.N.; funding acquisition, E.H. All authors have read and agreed to the published version of the manuscript.

Funding: This research received no external funding.

Institutional Review Board Statement: Not applicable.

Informed Consent Statement: Not applicable.

Data Availability Statement: The data presented in this study are available on request from the corresponding author. The data are not publicly available due to permission from owner.

Conflicts of Interest: The authors declare no conflict of interest. The funders had no role in the design of the study; in the collection, analyses, or interpretation of data; in the writing of the manuscript, or in the decision to publish the results. 


\section{References}

1. Liu, L.; Xu, J.; Liao, S.S.; Chen, H. A Real-Time Personalized Route Recommendation System for Self-Drive Tourists Based on Vehicle to Vehicle Communication. Expert Syst. Appl. 2014, 41, 3409-3417. [CrossRef]

2. Shaout, A.; Colella, D.; Awad, S. Advanced Driver Assistance Systems-Past, Present and Future. In Proceedings of the 2011 Seventh International Computer Engineering Conference (ICENCO'2011), Cairo, Egypt, 27-28 December 2011 ; pp. 72-82. [CrossRef]

3. BPS—Statictics Indonesia. Perkembangan Jumlah Kendaraan Bermotor Menurut Jenis, 1949-2016; BPS—Statictics Indonesia: Jakarta, Indonesia, 2018.

4. Naumann, M.; Lauer, M.; Stiller, C. Generating Comfortable, Safe and Comprehensible Trajectories for Automated Vehicles in Mixed Traffic. In Proceedings of the 2018 21st International Conference on Intelligent Transportation Systems (ITSC), Maui, HI, USA, 4-7 November 2018; pp. 575-582. [CrossRef]

5. Wedagama, D.M.P. The Influence of Mixed Traffic on Congestion Level. Int. J. GEOMATE 2019, 17, 18-25. [CrossRef]

6. Afrin, T.; Yodo, N. A Survey of Road Traffic Congestion Measures towards a Sustainable and Resilient Transportation System. Sustainability 2020, 12, 4660. [CrossRef]

7. European Conference of Ministers of Transportation. Managing Urban Traffic Congestion; OECD Publishing: Paris, France, 2007; Volume 9789282101. [CrossRef]

8. Zadobrischi, E.; Cosovanu, L.M.; Dimian, M. Traffic Flow Density Model and Dynamic Traffic Congestion Model Simulation Based on Practice Case with Vehicle Network and System Traffic Intelligent Communication. Symmetry 2020, 12, 1172. [CrossRef]

9. Alirezaei, M.; Onat, N.; Tatari, O.; Abdel-Aty, M. The Climate Change-Road Safety-Economy Nexus: A System Dynamics Approach to Understanding Complex Interdependencies. Systems 2017, 5, 6. [CrossRef]

10. Akin, D.; Sisiopiku, V.P.; Skabardonis, A. Impacts of Weather on Traffic Flow Characteristics of Urban Freeways in Istanbul. Procedia-Soc. Behav. Sci. 2011, 16, 89-99. [CrossRef]

11. Rahman, F.I.; Hasnat, A.; Lisa, A.A. Traffic Flow Prediction by Incorporating Weather Information in Naïve Bayes Classifier. J. Adv. Civ. Eng. Pract. Res. 2019, 8, 10-16.

12. Omranian, E.; Sharif, H.; Dessouky, S.; Weissmann, J. Exploring Rainfall Impacts on the Crash Risk on Texas Roadways: A Crash-Based Matched-Pairs Analysis Approach. Accid. Anal. Prev. 2018, 117, 10-20. [CrossRef] [PubMed]

13. Ali, Q.; Yaseen, M.R.; Khan, M.T.I. The Impact of Temperature, Rainfall, and Health Worker Density Index on Road Traffic Fatalities in Pakistan. Environ. Sci. Pollut. Res. 2020, 27, 19510-19529. [CrossRef] [PubMed]

14. Afshari, A.; Schuch, F.; Marpu, P. Estimation of the Traffic Related Anthropogenic Heat Release Using BTEX Measurements-A Case Study in Abu Dhabi. Urban Clim. 2018, 24, 311-325. [CrossRef]

15. Khalifa, A.; Bouzouidja, R.; Marchetti, M.; Buès, M.; Bouilloud, L.; Martin, E.; Chancibaut, K. Individual Contributions of Anthropogenic Physical Processes Associated to Urban Traffic in Improving the Road Surface Temperature Forecast Using TEB Model. Urban Clim. 2018, 24, 778-795. [CrossRef]

16. Gładyszewska-Fiedoruk, K.; Teleszewski, T.J. Modeling of Humidity in Passenger Cars Equipped with Mechanical Ventilation. Energies 2020, 13, 2987. [CrossRef]

17. Francisco, A.; Esteban, C.; Calatayud, C.; Sanmartin, J. Speed and Road Accidents: Behaviors, Motives, and Assessment of the Effectiveness of Penalties for Speeding. Am. J. Appl. Psychol. 2013, 1, 58-64. [CrossRef]

18. Huang, Y.; Sun, D.J.; Zhang, L.H. Effects of Congestion on Drivers' Speed Choice: Assessing the Mediating Role of State Aggressiveness Based on Taxi Floating Car Data. Accid. Anal. Prev. 2018, 117, 318-327. [CrossRef] [PubMed]

19. Susilo, B.H.; Imanuel, I. Traffic Congestion Analysis Using Travel Time Ratio and Degree of Saturation on Road Sections in Palembang, Bandung, Yogyakarta, and Surakarta. MATEC Web Conf. 2018, 181, 1-10.

20. Ferreira, H.; Rodrigues, C.M.; Pinho, C. Impact of Road Geometry on Vehicle Energy Consumption and CO2 Emissions: An Energy-Efficiency Rating Methodology. Energies 2019, 13, 119. [CrossRef]

21. Yao, Z.; Hu, R.; Jiang, Y.; Xu, T. Stability and Safety Evaluation of Mixed Traffic Flow with Connected Automated Vehicles on Expressways. J. Safety Res. 2020, 75, 262-274. [CrossRef] [PubMed]

22. Das, A.K.; Saw, K.; Katti, B.K. Traffic Congestion Modelling Under Mixed Traffic Conditions Through Fuzzy Logic Approach: An Indian Case Study of Arterial Road. In Proceedings of the 12th Transportation Planning and Implementation Methodologies for Developing Countries (TPMDC), Bombay, India, 19-21 December 2016.

23. Husni, E.; Nasution, S.M.; Kuspriyanto; Yusuf, R. Predicting Traffic Conditions Using Knowledge-Growing Bayes Classifier. IEEE Access 2020, 8, 191510-191518. [CrossRef]

24. Kumar, K.; Parida, M.; Katiyar, V.K. Short Term Traffic Flow Prediction for a Non Urban Highway Using Artificial Neural Network. Procedia-Soc. Behav. Sci. 2013, 104, 755-764. [CrossRef]

25. Hu, W.; Liu, Y.; Li, L.; Xin, S. The Short-Term Traffic Flow Prediction Based on Neural Network. In Proceedings of the 2nd International Conference on Future Computer and Communication, Wuhan, China, 21-24 May 2010.

26. Nasution, S.M.; Husni, E.; Yusuf, R.; Kuspriyanto. Semi-Ensemble Learning Using Neural Network for Classifying Traffic Condition. In Proceedings of the 6th International Conference on Information Technology Systems and Innovation, ICITSI 2020, Bandung, Indonesia, 19-23 October 2020. [CrossRef]

27. Yi, H.; Jung, H.; Bae, S. Deep Neural Networks for Traffic Flow Prediction. In Proceedings of the IEEE international conference on big data and smart computing (BigComp), Jeju Island, Korea, 13-16 February 2017. 
28. Lv, Y.; Duan, Y.; Kang, W.; Li, Z.; Wang, F.-Y. Traffic Flow Prediction With Big Data: A Deep Learning Approach. Intell. Transp. Syst. IEEE Trans. 2014, 16, 1-9. [CrossRef]

29. Kumar, S.V.; Vanajakshi, L. Short-Term Traffic Flow Prediction Using Seasonal ARIMA Model with Limited Input Data. Eur. Transp. Res. Rev. 2015, 7, 1-9. [CrossRef]

30. Chen, E.; Ye, Z.; Wang, C.; Xu, M. Subway Passenger Flow Prediction for Special Events Using Smart Card Data. IEEE Trans. Intell. Transp. Syst. 2020, 21, 1109-1120. [CrossRef]

31. Sujatha, R.; Nithya, R.A.; Subhapradha, S.; Srinithibharathi, S. Decision Tree Classification for Traffic Congestion Detection Using Data Mining. Int. J. Eng. Tech. 2018, 4, 166-173.

32. Khan, S.Z.; Rahuman, W.M.A.; Dey, S.; Anwar, T.; Kayes, A.S.M. Road Crowd: An Approach to Road Traffic Forecasting at Junctions Using Crowd-Sourcing and Bayesian Model. In Proceedings of the International Conference on Research and Innovation in Information Systems (ICRIIS), Langkawi Island, Malaysia, 16-17 July 2017; pp. 1-6. [CrossRef]

33. Anitha, E.B.; Aravinth, R.; Deepak, S.; Jotheeswari, R.; Karthikeyan, G. Prediction of Road Traffic Using Naive Bayes Algorithm. Int. J. Eng. Res. Technol. 2019, 7, 1-4.

34. Sumari, A.; Ahmad, A.; Wuryandari, A. Knowledge Growing System: A New Perspective on Artificial Intelligence. In Proceedings of the 5th International Conference Information \& Communication Technology and System, London, UK, 20-21 February 2009.

35. Sumari, A.D.W.; Ahmad, A.S.; Wuryandari, A.I.; Sembiring, J.; Widjajati, F.A. An Introduction To Knowledge-Growing System: A Novel Field in Artificial Intelligence. JUTI J. Ilm. Teknol. Inf. 2010, 8, 11. [CrossRef]

36. Li, D.; Yang, M.; Jin, C.J.; Ren, G.; Liu, X.; Liu, H. Multi-Modal Combined Route Choice Modeling in the MaaS Age Considering Generalized Path Overlapping Problem. IEEE Trans. Intell. Transp. Syst. 2021, 22, 2430-2441. [CrossRef]

37. Cao, Q.; Ren, G.; Li, D.; Ma, J.; Li, H. Semi-Supervised Route Choice Modeling with Sparse Automatic Vehicle Identification Data. Transp. Res. Part C Emerg. Technol. 2020, 121, 102857. [CrossRef]

38. Ben-Akiva, M.E.; Ramming, M.S.; Bekhor, S. Route Choice Models. In Human Behaviour and Traffic Networks; Springer: Berlin/Heidelberg, Germany, 2004; pp. 23-45. [CrossRef]

39. Prato, C.G. Route Choice Modeling: Past, Present and Future Research Directions. J. Choice Model. 2009, 2, 65-100. [CrossRef]

40. Namoun, A.; Tufail, A.; Mehandjiev, N.; Alrehaili, A.; Akhlaghinia, J.; Peytchev, E. An Eco-Friendly Multimodal Route Guidance System for Urban Areas Using Multi-Agent Technology. Appl. Sci. 2021, 11, 2057. [CrossRef]

41. Ge, Y.; Li, H.; Tuzhilin, A. Route Recommendations for Intelligent Transportation Services. IEEE Trans. Knowl. Data Eng. 2021, 33, 1169-1182. [CrossRef]

42. Yang, Z.S.; Cai, C.Q.; Bao, L.X. Intelligent In-Vehicle Control and Navigation Based on Multi-Route Traffic Optimization. In Proceedings of the International Conference on Machine Learning and Cybernetics, Dalian, China, 13-16 August 2006; pp. 962-966. [CrossRef]

43. Wu, C.; le Vine, S.; Sivakumar, A.; Polak, J. Dynamic Pricing of Free-Floating Carsharing Networks with Sensitivity to Travellers' Attitudes towards Risk. Transportation 2021, 2019, 16. [CrossRef]

44. Ma, J.; Xu, M.; Meng, Q.; Cheng, L. Ridesharing User Equilibrium Problem under OD-Based Surge Pricing Strategy. Transp. Res. Part B Methodol. 2020, 134, 1-24. [CrossRef]

45. Das, P.; Ribas-Xirgo, L. Parameter Estimation for Optimal Path Planning in Internal Transportation. CoRR 2018, arXiv:1808.00522.

46. Qu, Y.; Li, L.; Liu, Y.; Chen, Y. Travel Routes Estimation in Transportation Systems Modeled by Petri Nets. In Proceedings of the 2010 IEEE International Conference on Vehicular Electronics and Safety, QingDao, China, 15-17 July 2010; pp. 73-77.

47. Zhou, S.; Yan, X. Driver's Route Choice Model Based on Traffic Signal Control. In Proceedings of the 3rd IEEE Conference on Industrial Electronics and Applications, Singapore, 3-5 June 2008; pp. 2331-2334. [CrossRef]

48. Sayarshad, H.R.; Mahmoodian, V.; Bojović, N. Dynamic Inventory Routing and Pricing Problem with a Mixed Fleet of Electric and Conventional Urban Freight Vehicles. Sustainability 2021, 13, 6703. [CrossRef]

49. He, Z.; Chen, K.; Chen, X. A Collaborative Method for Route Discovery Using Taxi Drivers' Experience and Preferences. IEEE Trans. Intell. Transp. Syst. 2018, 19, 2505-2514. [CrossRef]

50. Kazhaev, A.; Almetova, Z.; Shepelev, V.; Shubenkova, K. Modelling Urban Route Transport Network Parameters with Traffic, Demand and Infrastructural Limitations Being Considered. In Proceedings of the IOP Conference Series Earth and Environmental Science, Moscow, Russia, 18 May 2018. [CrossRef]

51. Paiva, S.; Pañeda, X.G.; Corcoba, V.; García, R.; Morán, P.; Pozueco, L.; Valdés, M.; del Camino, C. User Preferences in the Design of Advanced Driver Assistance Systems. Sustainability 2021, 13, 3932. [CrossRef]

52. Jung, J.; Park, S.; Kim, Y.; Park, S. Route Recommendation with Dynamic User Preference on Road Networks. In Proceedings of the IEEE International Conference on Big Data and Smart Computing (BigComp), Kyoto, Japan, 27 March 2019 ; pp. 1-7. [CrossRef]

53. Bin, C.; Gu, T.; Sun, Y.; Chang, L.; Sun, L. A Travel Route Recommendation System Based on Smart Phones and IoT Environment. Wirel. Commun. Mob. Comput. 2019, 2019, 1-16. [CrossRef]

54. Litzinger, P.; Navratil, G.; Sivertun, Å.; Knorr, D. Using Weather Information to Improve Route Planning. In Bridging the Geographic Information Sciences; Springer: Berlin/Heidelberg, Germany, 2012. [CrossRef]

55. Gandotra, N.; Bajaj, R.K.; Gupta, N. Vendor Selection under Intuitionistic Trapezoidal Fuzzy Multiple Criteria Decision Making Model with Entropy Weights. In Proceedings of the International Conference on Advances in Computing and Communications, Washington, DC, USA, 9-11 August 2012. 
56. Yuen, K.K.F. A Multiple Criteria Decision Making Approach for E-Learning Platform Selection: The Primitive Cognitive Network Process. In Proceedings of the Computing, Communications and Applications Conference, Hong Kong, China, 11-13 January 2012.

57. Nasution, S.M.; Husni, E.; Kuspriyanto; Yusuf, R.; Mulyawan, R. Road Information Collector Using Smartphone for Measuring Road Width Based on Object and Lane Detection. Int. J. Interact. Mob. Technol. 2020, 14, 42-61. [CrossRef]

58. Patro, S.G.K.; Sahu, K.K. Normalization: A Preprocessing Stage. Int. Adv. Res. J. Sci. Eng. Technol. 2015, 2, 06462. [CrossRef]

59. Mustaffa, Z.; Yusof, Y. A Comparison of Normalization Techniques in Predicting Dengue Outbreak. In Proceedings of the International Conference on Information and Finance (ICIF 2010), Kuala Lumpur, Malaysia, 26-28 November 2010.

60. Roth, C.; Kesdogan, D. A Privacy Enhanced Crowdsourcing Architecture For Road Information Mining Using Smartphones. In Proceedings of the IEEE 11th Conference on Service-Oriented Computing and Applications (SOCA), Paris, France, 20-22 November 2018.

61. Putri, S.A.; Wahono, R.S. Integrasi SMOTE Dan Information Gain Pada Naive Bayes Untuk Prediksi Cacat Software. J. Softw. Eng. 2015, 1, 86-91.

62. Kuhn, M.; Johnson, K. Applied Predictive Modeling; Springer: New York, NY, USA, 2013. [CrossRef] 